\title{
Dry Weather Extremes of Sri Lanka and Impact of Southern Oscillation
}

\author{
R.M.S.S. Sanjeewani ${ }^{*}$, L. Manawadu ${ }^{2}$ \\ ${ }^{I}$ Department of Transport and Logistics Management, University of Moratuwa, Sri Lanka \\ ${ }^{2}$ Department of Geography, University of Colombo, Sri Lanka \\ *ranabahu.sss@gmail.com
}

\begin{abstract}
Occurrence of lengthier dry spells is becoming a common phenomenon in most parts of the world and it is an exigent challenge to adapt the changing climate. World Meteorological Organisation defines an index to calculate the frequency of consecutive dry days (CDD) to identify dry extremes and it is timely important to identify spatial and temporal characteristics of these dry extremes as a country.

This study focused on identifying the spatial and temporal trends of consecutive dry days in Sri Lanka from 1981 to 2010 and considers the impact of southern oscillation on the occurrence of dry extremes of Sri Lanka as one of the causal factor. Extremes were identified using the daily rainfall data using RClimDex 1.0 package. Dry extremes were mapped to derive the spatial and temporal characteristics. Non-parametric Mann Kendall test is used to detect the trends and their significance.
\end{abstract}

Average frequencies of consecutive dry days in 1982, 1983, 1987, 1992 and 1998 were much higher than that of the other years. Inversely lower annual averages of frequency of consecutive dry days were seen in 1985, 1991, 2003 and 1981. Most of these extreme cases highly coincided with the behavioral pattern of southern oscillation index. However, all the lengthier dry spells were not due to the southern oscillation and the causes should be further investigated for better decision making. Spatially there was a significant decreasing trend of consecutive dry days in Puttalam, Hambanthota, Nuwara Eliya and Rathnapura while the decreasing trends of other regions were not statistically significant. According to the research outputs it is clear these decreasing trends of CDDs are fair signs for dry zonal regions including Puttalam and Hambanthota. However, the significant decreasing trends of CDDs in Ratnapura may let to consider whether this region is getting wetter and wetter incurring number of issues including floods and adverse impacts on plantations. Hence, appropriate adaptation methods should be rectified to cope with the changing climate.

Keywords: Consecutive dry days, Spatial temporal trends, RClimDex, Non-parametric Mann Kendall trend test, Southern oscillation 